University of Nebraska - Lincoln

DigitalCommons@University of Nebraska - Lincoln

Faculty Publications: Department of Entomology

$1-1911$

\title{
THE PRESENT METHODS OF TEACHING ENTOMOLOGY
}

Herbert Osborn

Ohio State University

Follow this and additional works at: https://digitalcommons.unl.edu/entomologyfacpub

Part of the Entomology Commons, and the Science and Mathematics Education Commons

Osborn, Herbert, "THE PRESENT METHODS OF TEACHING ENTOMOLOGY" (1911). Faculty Publications: Department of Entomology. 524.

https://digitalcommons.unl.edu/entomologyfacpub/524

This Article is brought to you for free and open access by the Entomology, Department of at DigitalCommons@University of Nebraska - Lincoln. It has been accepted for inclusion in Faculty Publications: Department of Entomology by an authorized administrator of DigitalCommons@University of Nebraska - Lincoln. 
President Sanderson: Professor Osborn will present the next paper.

\section{THE PRESENT METHODS OF TEACHING ENTOMOLOGY}

\section{By Herbert Osbonn, Ohio State University}

In a discussion of the methods of teaching entomology, it is almost necessary to take a hasty view of the growth of the subject and of the different methods of imparting knowledge in it during the past half century. We need scarcely go back of this, because for the United States, at least, the growth of the teaching of entomology as a subject included in a college curriculum has had its growth within that time. In fact, practically all of the development of the teaching outside of two or three localities has been within the last twenty-five 'years. Naturally the methods in vogue in the early teaching of the subject were derived from the teaching of related subjects such as Botany and Geology, but even for these the different programs of instruction were in a very crude form up to thirty or forty years ago: The growth of the methods of teaching has necessarily followed the growth of the subject as an application for economic purposes as well as for the impartation of knowledge as a science. Naturally, then, for the teaching of Economic Entomology the development of methods must have been within very recent time.

The early plan of teaching was quite naturally that of the lecture systemi, partly because of the scattered condition of the material and lack of definite texts in the science, and partly because of the prevalent idea that the lecture system was the most satisfactory and, perhaps, the least troublesome to the teacher. Later, however, this was combined with more or less of field work, and then with some laboratory courses, and at the present time the method which I suspect is the most general is a combination of these various methods; that is, more or less of the lecture system including illustrations by chart or lantern, or collection incorporated in class work, along with text references and quizzes. These associated with definite laboratory courses, with dissections of typical forms, and a definite allotment of field work involving the collection of material in its natural habitat, its preparation for preservation, and more or less of identification for the practice in systematic work. These methods, of course, vary with regard to 
the preparation of the students and the progress they have made in their studies. For more advanced work it includes the most precise methods of microscopical study and all of the refinements that have been evolved with reference to the study of minute anatomy and the special methods of field research to determine ecologic conditions.

Entertaining lectures about insects or insect habits, while they may still have value as inciting interest in the subject, but which are largely forgotten at the end of the term, go a very short distance in the way of effective training for exact, scientific work in entomology. This must come by continued and concentrated individual application. It can be stimulated but not accomplished by the efforts of the teacher.

At present we may consider that there are at least three phases of the teaching of the subject to be considered: First, the instruction given in scientific institutions, and especially with reference to the training of investigators or teachers who expect to follow the work from a professional standpoint; second, the instruction given in agricultural colleges or other schools especially for the purpose of giving information to those who will use it in the application of measures of control for the insects with which they have to contend in their daily life work; and third, the instruction which is now becoming an important feature given in the shape of extension courses to people outside of college and school environment, and which takes the form of lecture work in the extension course or the publication of instructive matter in agricultural journals or other media of publication.

It is evident that the methods available in these different lines of instruction must vary, and that while each has its very important place, the effort should be to adopt methods which will be most effective in the different spheres. This may involve the utilization of teachers of quite different capacity or training, but, nevertheless, it appears to me must involve for each a thorough and accurate foundation in the essentials of the science. As for the necessity of the different lines, it is clear that there can be no definite progress in the matter of thorough training for the two latter groups except as we have the solid basis of fact determined by accurate and prolonged study of the conditions upon which to base the instruction given. There is, therefore, the necessity that we should have trained investigators for the acquisition of further knowledge concerning insects, the discovery of which is one of the most important duties of modern entomology. For the purpose of this kind of instruction it is absolutely necessary that there be thorough training in related sciences, as well as in the general foundation in other branches of knowledge. It appears to me that the work in this line should naturally be built upon as thorough a foundation as required for advanced training in any line of knowledge. Ento- 
mology is distinctly a special branch of science, and in order to secure a breadth of view or to acquire for it the proper outlook, it should not be entered upon, at least for its special features, until the student has been thoroughly grounded in those branches of knowledge which he must use in the furtherance of his work. I believe that a thorough course in zoölogy should by all means precede the special study of entomology, and if with this there can be extended work in botany and geology, as well as chemistry and physics, the student is so much the better qualified to secure a proper perspective and to accomplish effective work either in investigation or instruction.

The equipment for the teaching of this subject is pretty well established, and there is I think considerable agreement in the different institutions where the subject is seriously taught. In practically every institution which I have visited recently I have found that there is a full recognition of the necessity for a collection of insects which shall be representative of the different orders for service as a basis for the identification of species, and where advanced work is attempted, serve for the investigation of various groups and sometimes for theses on monographic subjects. That collections in entomology should be even more essential than in general zoölogy is quite a natural result. of the immense numbers of species with which we have to deal, and the fact that specific recognition is such a fundamental necessity in the proper handling of economic as well as of morphologic problems.

Equally important with the collection is the equipment of apparatus, microscopes, etc., which are essential in the detailed anatomical and morphologic studies, and with these there will be in all cases a necessity for facilities for the tracing of life histories and the study of problems of development. Just how far this matter shall go is evidently a question of opinion, or in some cases a question of resources, since the building of elaborate insectaries is a matter of considerable expense. That there shall be some provision for controlling the conditions and facilitating observation in life histories is granted, but it is evident that very much in the way of thorough training can be done in the field, and with moderate equipment in this direction.

I have had an opportunity to visit a large number of institutions where departments of Entomology were at work, and it has happened in a great many instances that the insectaries have just at the time of my visit been unused because the problems on which the entomologists were engaged were being conducted from the field and laboratory standpoint. This has occurred so frequently that I have been somewhat puzzled to know whether the insectaries furnished so much of advantage as they were expected to, but nevertheless I am very free to grant that there are many problems in which they must be of great 
service, and both for instructional purposes and investigation must have a place. For the purpose of instruction $I$ am inclined to think that they will be of the greatest service in connection with work laid out for advanced students, and that for the more elementary students better results can be obtained by field and laboratory methods.

The extent to which a department must be provided with books and such accessories is one in which I think we shall all agree that the more that can be secured the better, but I do not feel that any department need neglect the subject because of a scant equipment in this direction. If students are forced to go more directly to the subjects themselves there is certainly some advantage, although the access to extended literature is helpful, and for some subjects, absolutely indispensable.

The other element in the problem, and the most fundamental one of all appears to me to be the teacher, and here it is difficult to make any very specific statements. In the earlier development of the subject it seems 'to me that a great deal more depended upon the individuality of the teacher than at present. So much depends upon the stimulus given to the student as to his effective work that in the earlier development of the subject it was very largely a matter of this individual work. At present a student may acquire his enthusiasm from a number of associated workers and fellow students, as well as teachers, or be stimulated by the recognition of the fact that there is a distinct demand for workers in this field. My own feeling is that students should be given as great a freedom of action as possible, and that especially after they have entered upon advanced work the teacher should occupy the position of a helpful guide rather than that of a dictator in the work. A student who does not have enough interest and enthusiasm in the subject to work independently, or who does not have enough independence and originality in his work to go beyond the outlines furnished by his teacher, is in most cases hardly worth the extended effort of the teacher. If he is too distinctly directed in this course he will fail to branch out into lines which will be a means of growth to himself or of distinct advantage in the progress of the science.

As a concrete example of the courses of study in this line, it may be permissible for me to outline briefly the courses offered in my Department, with some hints as to the purpose and method in each.

The work in the College of Agriculture for four-year students begins with a year of general zoölogy, including considerable attention to economic phases of the subject and embracing a discussion of the group of insects, with indication of the orders, some life histories and habits, with certain applications for injurious forms. 
This course is followed by a year of general economic entomology, which is intended primarily as a course to give the elements of the subject in a broad way, but informing the students as to the divisions of the group, the principal phases of life cycles, especially those which are at the basis of measures for control, to discuss remedies, use of insecticides and apparatus, and in short to put the student where he may intelligently consult the literature of Entomology which is available in experiment station and other entomological reports and apply practical modes of treatment. The course includes for class work, lectures, quizzes and examinations, with laboratory work devoted to the dissection of typical examples in the different orders, carried far enough to give some acquaintance with both internal and external structures, and particularly with such structures as are at the foundation of classification. Students are also required to collect and prepare a representative series of insects with classification carried far enough so that they become acquainted with the various divisions used in this work.

Such a course, we believe, is fitted to prepare a student not only for the general work which may follow in any. field, but also to furnish a basis in case he determines by this time that he wishes to go further into the subject, or to make it his profession.

For advanced courses the student may start at the beginning of his third year in college by taking advanced entomology based upon the two years of preceding work, and for this course there is given a thorough review of the anatomy, physiology and development of insects with special attention to the phases of metamorphosis, or life cycles and adaptations which constitute such a very important basis for the problems of control. The scientific basis for methods of applying insecticides, the use of apparatus and the application of cultural methods, use of parasites, diseases, etc., are fully discussed. It also includes a practical study of the scale insects intended to cover an important economic group and as giving training in the technique and taxonomy of a group. In this connection also we usually discuss the questions of legislation, quarantine, inspections, etc., with, later, the selection of some particular group or species upon which a more exhaustive study is made. Such a study serves as a training in the use of entomological methods and to give a greater familiarity with apparatus, collections and library. Following this course which has occupied a year, a student may engage upon a year of special research work devoted to a particular problem. This may be taken in connection with a course in invertebrate embryology covering the various phases of development in the invertebrates at large with a considerable time in the study of the embryonic development of insects. 
There is also a course in invertebrate zoölogy which is open to election and which may be taken either before or in connection with the course in advanced entomology. This course, dealing with invertebrates in general and devoted to morphology, relationships and life histories, serves to give a broad knowledge of the phases of invertebrate life and to form a better basis for acquaintance with insect structure and development. It embraces especially disscctions, microscopical studies and special technique in preparation of material for study.

Advanced students are also expected to carry a course of seminary work, which includes reports upon current literature, reports upon the personal study of the student, or the discussion of such special scientific topics as may be of special interest during the time in which the course is running. This enables the student to gain practice not only in the preparation, but in the presentation of results in his work. For graduate students there is a requirement for the preparation of a thesis in which the student does practically all of the work which is common in the preparation for publication of an exhaustive scientific paper.

For the more elementary training there is offered a course to students of the short course, and others who have had no training in zoölogy, this course running through one year and being taught in a more elementary manner, simply on the basis of a lack of knowledge of general zoölogy. It aims to give an acquaintance with the groups of insects, especially those which are of economic importance, a study of the measures of control, and an effort to acquaint them with so much of the technique of the subject that they can intelligently use the reports of experiment stations and other general publications.

It appears to me that something along this line is the most essential thing to provide in the courses presented at institutes or in extension work, because there is certainly a considerable gap between the average cultivator and the entomological literature presented in agricultural journals, station bulletins and other published material. Whatever can be done to reduce this gap, to make our knowledge available to the public at large, is not only a desirable but an essential thing for the progress and utilization of economic entomology.

Considering the immense changes which have taken place in the teaching of entomology in the last quarter century and the rapid movement at the present time, it is certain that marked changes will occur in the future years, and probably one of the desirable things at the present time is to indicate if possible the lines along which such development may occur, or to suggest features of improvement. Otherwise, I take it this symposium would have no particular object.

It appears to me that there is need of still further specialization in 
the work of presenting entomological matter, and that there must be naturally a larger division of the subjects of entomology, so that certain phases of it may be presented by those who are most thoroughly equipped for the purpose. The time is evidently past when all the different branches of entomology can be presented thoroughly by a single individual. While it is desirable for the sake of sympathetic action and coöperation that each one should be acquainted with the lines of work engaged in by others, for the sake of real progress it is necessary that each one should restrict himself in special work to a linited branch. This means a differentiation into systematic, morphologic, physiologic, embryonic and ecologic groups at least, and it is hardly possible to speak of any one of these as being of greater importance than the others. Systematic work is absolutely essential for accurate indication of the forms on which work is done, and it in turn must be based on thorough acquaintance with structure and development. An acquaintance with the physiological activities must, I think, grow greatly in importance as the development of experimental work toward the control of insects is developed. At first sight knowledge of the early embryonic stages may seem less important than post embryonic development, but it has become more and more apparent that many problems which have ultimate economic importance are wrapped up in this phase of the subject.

In addition to these there are the special fields of medical entomology and of behavior which have developed into quite important subjects within the last few years. Both of these may be taught in connection with other more general matter, and on some accounts it appears to me that this is much the better plan, since it is then possible to preserve the practical relationships which are an important thing for the student to secure. Medical entomology, however, has been making such strides and is becoming so distinct a branch, that it may require more special treatment. It was noticeable in the Congresses held during the past year that one of the most prominent topics for discussion was the relation of zoölogy and entomology to medical science, and there were some very urgent pleas that these be given a greater measure of attention. Experimental zoölogy has also considerable to offer in the way of particular treatment, and is doubtless to be reckoned as one of the important lines for development. Here again, however, it appears to me that there is some advantage in the close association of this work with the more general work upon life histories and habits, and I am not sure that the advantage to be derived from close specialization in the subject will outweigh the loss from its separation from the more general phases of the subject. It is very evident indeed that much of this matter will specialize 
largely in the future. This will make it more and more difficult to completely cover the important phases of entomological work in one place, and will, I think, further require a greater amount of migration of students who wish to get the latest and best of methods in any particular branch. Such a migration of students, already somewhat in vogue, is, it seems to me, a very desirable feature both for securing a broadening effect upon the student from working with different individuals, and for the stimulating effect it has upon the instructors themselves.

With regard to the teaching of entomology in the lower grades of school work, there seems to me to be a distinct problem and one that is deserving of most careful attention. Under the name of Nature Study and other terms considerable of this work is already in progress or is being urged with greater or less force. It is a subject which interests the economic entomologist particularly, because the education of the general public in some of the fundamentals of the subject would permit him to make his results known with much greater facility. I have heretofore, in an address before this society in Boston twelve years ago, indicated the belief that it would be unfortunate to force such work into the lower grades of school work before wc have teachers sufficiently trained to give the work with a fair degree of success. It appears to me that to force such work in with incompetent or uninterested teachers would simply delay the longer the practical adoption of such work, and therefore be an unfortunate feature for entomological science. It seems to me necessary that accurate knowledge in such lines should be carried from the higher grades of school work downward, and that as soon as a fairly sufficient body of teachers is available, the extension of such work into the lower grades will be practicable. This period should be much nearer to us at the present time than it was a decade ago, as there has been a very extensive growth of interest in such work, and a large body of teachers more or less trained for the handling of such a subject. It is still a fact, however, that many of the teachers attempting such work have more enthusiasm than knowledge, and are no assistance in the real extension of interest. These conditions will undoubtedly improve rapidly as the subject becomes more widely understood and the demand for such information increases from the outside. There is so much at present being presented in the general magazines, in agricultural literature, and in the form of accessory school work, that it can be only a question of time that greater efficiency will follow.

President Sanderson: Professor Bruner will present the closing paper. 